\title{
ANÁLISE DA VULNERABILIDADE NATURAL À PERDA DE SOLO DE BARÃO DE COTEGIPE, RS
}

\author{
Franciele Francisca Marmentini Rovani ${ }^{1}$ \\ Roberto Cassol ${ }^{2}$ \\ Cássio Arthur Wollmann ${ }^{3}$ \\ João Paulo Delapasse Simioni ${ }^{4}$
}

Resumo: Esta pesquisa teve como objetivo analisar a vulnerabilidade natural à perda de solo do município de Barão de Cotegipe, RS. Para tanto, criou-se um banco de dados espaciais em um ambiente de Sistemas de Informações Geográficas com auxílio do software Spring versão 5.0.6. O mapa de vulnerabilidade natural à perda de solo foi elaborado com base nas informações referentes à geomorfologia, geologia, solos, vegetação e uso e ocupação da terra, de acordo com o grau de vulnerabilidade de cada informação, por meio da álgebra de mapas. Como resultado, destaca-se as unidades estáveis com predomínio dos processos formadores do solo, e as unidades moderadamente vulneráveis, prevalecendo os processos erosivos. Nas unidades em que predominou a vulnerabilidade natural, sugere-se especial atenção em relação ao meio natural e aos agentes que o influenciam, visando boas práticas sociais associadas às políticas ambientais no processo de tomada de decisões econômicas, possibilitando a valorização e proteção do meio.

Palavras-chave: Cartografia Ambiental; Geotecnologias; Vulnerabilidade Natural.

\section{NATURAL VULNERABILITY ANALYSIS TO SOIL LOSS IN THE CITY OF BARÃO DE COTEGIPE, RS}

Abstract: The study and the analysis of the spatial relation can be better understood and visualized through environmental maps that touch society to reality. Therefore, the objective of this research is to analyze the natural vulnerability to the soil loss in Barão de Cotegipe. However, a spatial database was created in an environment of Geographic Information with the support of Spring Software version 5.0.6. The map of natural vulnerability to the soil loss was made based on information related to geomorphology, geology, soil, vegetation and use of soil, according to vulnerability of the information throughout the algebra of maps. As a result, has been pointed stable units with predominant of process that formatted the soil and vulnerable moderated units, mainly the erosive processes. In the units that was predominated the natural vulnerability, the suggestion is to have a special attention in relation to natural environment and the agents that influence it. The aim is to have good

1. Doutoranda do Programa de Pós-Graduação em Geografia da Universidade Federal de Santa Maria. Bolsista de Doutorado Sanduíche no Exterior - SWE/CNPq (franciele.rovani@yahoo.com.br).

2. Profo. Dr. do Departamento de Geociências da Universidade Federal de Santa Maria (rtocassol@gmail.com).

3. Profo. Dr. do Departamento de Geociências e Coordenador dos cursos de Geografia da Universidade Federal de Santa Maria (cassio_geo@yahoo.com.br).

4. Mestrando do Programa de Pós-Graduação em Geografia da Universidade Federal do Rio Grande do Sul (jpaulosimioni@hotmail.com). 
social practices associated to environmental politics in the process of economic decisionmaking, which can make possible the environment value and protection.

Key words: Environmental Cartography; Geotechnologies; Natural Vulnerability

\section{INTRODUÇÃO}

Atualmente, as questões ambientais se tornaram objeto de estudo de muitas pesquisas e de discussões na sociedade, devido, principalmente, à realidade das condições ambientais e da qualidade de vida das pessoas. Os estudos sobre o meio ambiente, com o objetivo de compreender as relações entre a sociedade e a natureza de forma integradora, holística, precisam se preocupar não somente no levantamento de problemas ambientais causados pela sociedade e como solucioná-los, mas também no estudo do grau de fragilidade dos diversos ambientes às interferências antrópicas (LIMA; MARTINELLI, 2008).

Deste modo desenvolveram-se diversos instrumentos de pesquisas para análise dos componentes sociais e ambientais de maneira integradora destacando-se o Zoneamento Ecológico-Econômico (ZEE) que pode ser entendido como um "instrumento técnico e político de planejamento das diferenças, segundo critérios de sustentabilidade, de absorção de conflitos e de temporalidade, configurando um processo dinâmico, que deve ser revisto e atualizado periodicamente" (MEDEIROS, 1999, p. 3).

Esse instrumento visa expressar o resultado de dois processos dinâmicos que integram o território: os processos naturais, compreendidos como sendo aqueles parâmetros geobiofísicos que compõem o ambiente, e os processos sociais, que dizem respeito à dinâmica socioeconômica e aos objetivos políticos (CAMPAGNANI; SANTOS, 1998). Concordando ainda com os autores, o ZEE apresenta informações sobre o território necessárias para planejar a sua ocupação racional e o uso sustentável dos recursos naturais, integradas em uma base geográfica de dados. Além disso, é possível identificar áreas do território, segundo potencialidades e vulnerabilidades, fundamentais para o processo de compreensão do cenário atual, integrando políticas públicas e colaborando para o processo de tomada de decisões para ordenamento do território.

A carta de vulnerabilidade natural, de acordo com Becker e Egler (1996), baseada no princípio da ecodinâmica de Tricart (1977), considera os processos de morfogênese e 
pedogênese a partir da análise integrada (solo, rocha, vegetação). Já, a carta de potencialidade social considera a relação entre os fatores dinâmicos e os fatores restritivos de acordo com os dados econômicos, sociais e políticos. A integração de ambas as cartas resulta em uma carta-síntese de acordo com a potencialidade ou vulnerabilidade da paisagem.

Simões et al. (1998, p. 4) salienta que "o conhecimento da vulnerabilidade natural é fundamental para prever o comportamento futuro dos sistemas naturais diante do processo de ocupação e adensamento da atividade social". Além disso, enfatiza que "a análise da potencialidade social deve buscar identificar a capacidade das unidades territoriais em construírem-se em espaços de mudança, isto é, gerar, difundir e absorver inovações que promovam o desenvolvimento endógeno..." (SIMÕES et al., 1998, p. 4).

Assim, justifica-se a necessidade de desenvolver estudos que analisem a paisagem sob o enfoque integrado, que priorizem a dinâmica da paisagem e representem cartograficamente os aspectos sociais e naturais, servindo como guias de orientação e implementação para planejadores municipais. Para tanto, esta pesquisa visou identificar e diagnosticar a vulnerabilidade natural à perda do solo do município de Barão de Cotegipe, localizado ao norte do estado do Rio Grande do Sul e que compreende um território de 260,09 km² (Figura 1).

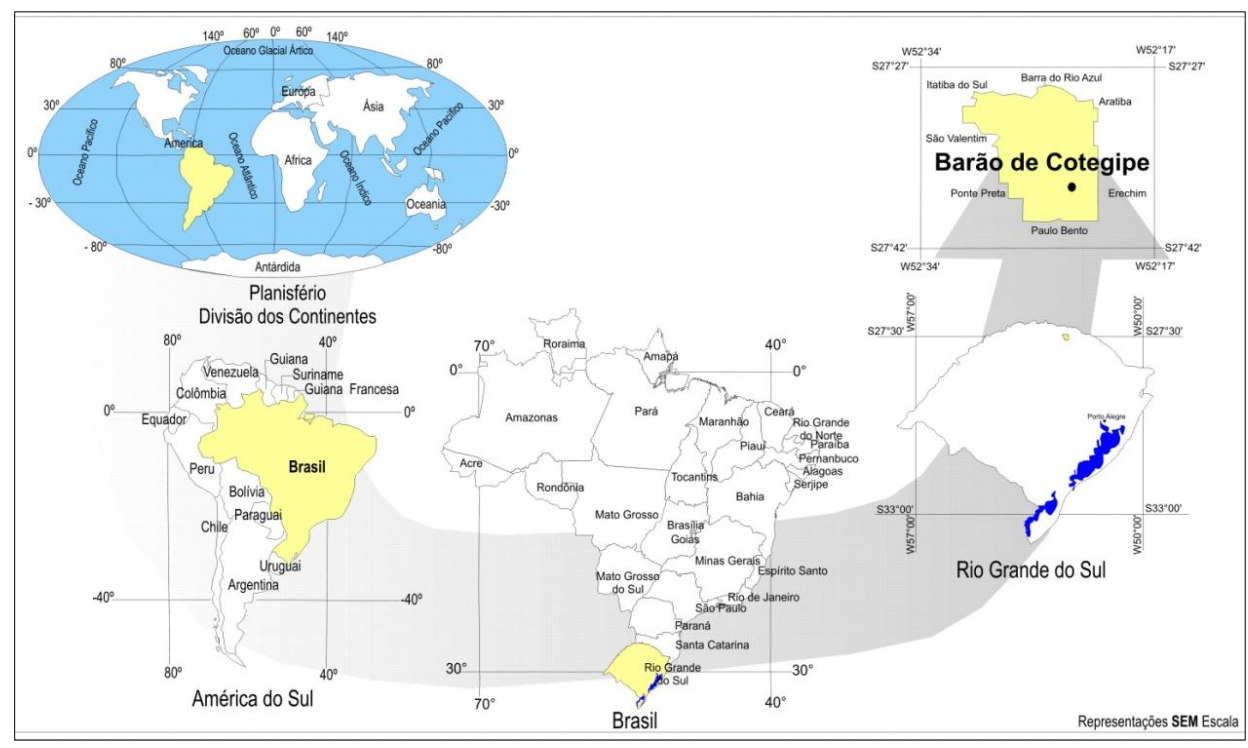

Figura 1: Localização do município de Barão de Cotegipe/RS. Fonte: Rovani (2013). 


\section{MATERIAIS E MÉTODOS}

Para o desenvolvimento desta pesquisa foi usada a base cartográfica do Município, obtida das cartas topográficas elaboradas pela 1a Divisão de Levantamento do Exército, folhas SG.22-Y-D-I-3, SG.22-Y-C-VI-2, SG.22-Y-D-VI-1 e SG.22-Y-C-III-4. Utilizou-se uma imagem de satélite do satélite Landsat 5 adquirida junto ao Instituto Nacional de Pesquisas Espaciais (INPE) para a elaboração do Mapa de Uso e Cobertura da Terra e mapas temáticos de Geologia (IBGE, 2003a), Geomorfologia (IBGE, 2003b) e Solos (IBGE, 2003c), obtidos junto ao Instituto Brasileiro de Geografia e Estatística (IBGE) na escala 1:250000, Folha Erechim/Lages SG.22-Y-D/Z-C.

$\mathrm{Na}$ análise da vulnerabilidade natural à perda de solo observou-se a metodologia proposta por Crepani et al. (1996, 2008), que propõe inicialmente a delimitação de Unidades Territoriais Básicas (UTBs) da área de estudo com base na imagem de satélite. Posteriormente foram elaborados os mapas temáticos de solos, geomorfologia, geologia e vegetação/e uso da terra. Estas informações foram integradas no banco de dados do SIG Spring versão 5.0.6. Concomitantemente a elaboração dos mapas temáticos foi efetuada a integração dos dados por meio da álgebra de mapas, visando a obtenção do mapa síntese das informações, como resultado final.

\section{AVALIAÇÃO DA VULNERABILIDADE NATURAL À PERDA DE SOLO}

A análise da vulnerabilidade natural à perda de solo foi elaborada com base na metodologia proposta por Crepani et al. (1996, 2008), para subsidiar o ZEE da Amazônia. Essa metodologia foi desenvolvida a partir do conceito de ecodinâmica de Tricart (1977), baseado na relação morfogênese/pedogênese, e da potencialidade para estudos integrados das imagens de satélite Landsat, visto que permitem uma visão sinóptica e holística da paisagem (CREPANI et al., 1996).

De acordo com a metodologia, primeiramente elaborou-se o mapa das unidades homogêneas de paisagem, denominado de Unidades Territoriais Básicas (UTBs), que foi obtido através da análise, interpretação e classificação da imagem de satélite. Em seguida, foram elaborados os mapas temáticos de geomorfologia, geologia, solos e vegetação/uso da 
terra e associados ao mapa de unidades territoriais, por meio da álgebra de mapas, identificando e caracterizando as unidades ambientais.

A classificação do grau de estabilidade ou vulnerabilidade (resistência ao processo natural à erosão) de cada unidade foi realizada segundo as relações de morfogênese e pedogênese, a partir da análise integrada das rochas, do solo, do relevo e da vegetação. Desse modo, quando predominou a morfogênese, prevaleceram os processos erosivos modificadores da forma do relevo, e, quando predominou a pedogênese, prevaleceram os processos formadores do solo. A vulnerabilidade foi expressa pela atribuição de valores de estabilidade em uma escala de 1 a 3 para cada unidade de paisagem (Tabela 1).

\begin{tabular}{|l|l|c|}
\hline \multicolumn{1}{|c|}{ UNIDADE } & \multicolumn{1}{|c|}{ RELAÇÃO PEDOGÊNESE/MORFOGÊNESE } & VALOR \\
\hline Estável & Prevalece a pedogênese & 1,0 \\
\hline Intermediária & Equilíbrio entre a pedogênese e a morfogênese & 2,0 \\
\hline Instável & Prevalece a morfogênese & 3,0 \\
\hline
\end{tabular}

Tabela 1: Avaliação da estabilidade/vulnerabilidade das unidades de paisagem de acordo com a relação pedogênese/morfogênese.

Fonte - Crepani et al. (1996), modificada de Tricart (1977).

Para a definição e atribuição dos valores de vulnerabilidade/estabilidade de cada classe temática, fez-se necessário seguir alguns critérios propostos por Crepani et al. (1996, 2008): geomorfologia - formas do relevo e os índices morfométricos referentes à dissecação do relevo pela drenagem e amplitude altimétrica; geologia - história e evolução do ambiente geológico (grau de coesão das rochas); solos - considerou-se o grau de desenvolvimento dos solos (processos de formação de solos ou de relevo); e vegetação/uso e cobertura da terra observou-se os tipos de uso e a densidade da cobertura vegetal.

Deste modo, as classes de cada mapa temático foram substituídas pelos valores de vulnerabilidade, em uma escala variando de 1 a 3, preestabelecidos no SIG. Em seguida, por meio das operações de álgebra de mapas utilizando a linguagem de programação do software Spring, os atributos de cada mapa foram integrados, apresentando como resultado final um mapa síntese com cinco classes temáticas (Tabela 2). As unidades mais estáveis apresentaram valores próximos a 1,0, as intermediárias, próximos a 2,0 e as unidades mais vulneráveis, próximos a 3,0. 


\begin{tabular}{|l|c|l|}
\hline \multicolumn{1}{|c|}{ GRAU DE VULNERABILIDADE } & INTERVALO DE VALORES & \multicolumn{1}{c|}{ VARIÁVEL VISUAL COR* } \\
\hline Estável & 1,0 a 1,3 & R: 0 / G: 0 / B: 255 \\
\hline Moderadamente Estável & 1,4 a 1,7 & R: 0 / G: 255 / B: 255 \\
\hline Medianamente Estável/Vulnerável & 1,8 a 2,2 & R: 0 / G: 255 / B: 0 \\
\hline Moderadamente Vulnerável & 2,3 a 2,6 & R: 255 / G: 255 / B: 0 \\
\hline Vulnerável & 2,7 a 3,0 & R: 255 / G: 0 / B: 0 \\
\hline
\end{tabular}

Tabela 2: Representação dos valores e das classes de estabilidade/vulnerabilidade das unidades de paisagem.

* As cores utilizadas na representação do Mapa Vulnerabilidade pertencem ao sistema RGB (red, green,blue). Fonte: Modificado de Crepani et al. (1996).

\section{RESULTADOS E DISCUSSÕES}

Como resultados desta pesquisa destacam-se os mapas de solos, geomorfologia, geologia, vegetação/uso e ocupação da terra, que a partir de sua integração por meio da álgebra de mapas, geraram o mapa síntese de vulnerabilidade natural à perda de solo.

\section{Solos}

De acordo com o mapa de solos do IBGE (2003c), foram identificados três tipos de solos no município de Barão de Cotegipe (Figura 2), pertencentes às classes de Cambissolos, Latossolos e Neossolos, na escala 1:250000.

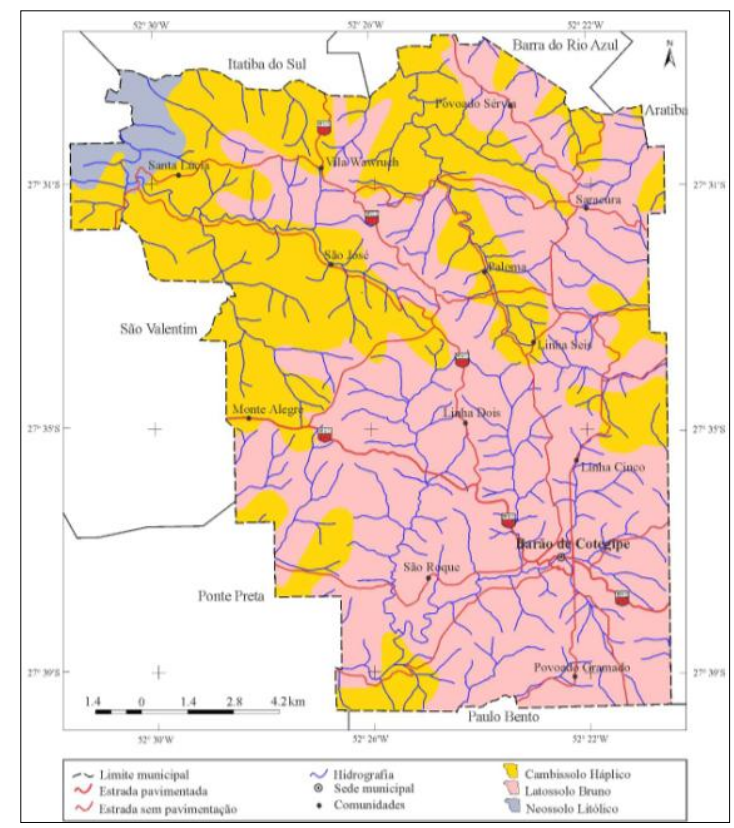

Figura 2: Mapa de Solos do município de Barão de Cotegipe/RS.

Elaboração - Rovani (2013)

Fonte: IBGE (2003c) 
Os Cambissolos são solos rasos a profundos, constituídos por material mineral, com horizonte B incipiente, variando de bem drenados a imperfeitamente drenados, e estão em processo de transformação (EMBRAPA, 2006; STRECK et al., 2008). No município, destacouse a presença dos Cambissolos Háplicos, que se caracterizam por não serem húmicos e nem de caráter flúvico. Localizam-se especialmente na porção norte, representando $36,63 \%$ da área, e, por serem originados de basalto, apresentam melhor fertilidade química em relação aos solos originados de riolito ou granito, recebendo valor de vulnerabilidade 2,0.

Os Latossolos são solos normalmente profundos e homogêneos (transição difusa ou gradual dos horizontes), altamente intemperizados, com predomínio de caulinita e óxidos de ferro e bem drenados (STRECK et al., 2008). Os Latossolos Brunos, encontrados desde a porção sul estendendo-se até o norte do município, ocupando $60,82 \%$ do território, são considerados solos mais estáveis (valor 1,0), em função de suas características físicas (profundos, bem drenados, muito porosos, bem estruturados) e pela boa aptidão agrícola.

Os Neossolos compreendem solos constituídos por material mineral ou por material orgânico pouco espesso, pois são solos novos, pouco desenvolvidos a partir dos mais diversos tipos de rochas (EMBRAPA, 2006; STRECK et al., 2008). Destacam-se ainda, no município, os Neossolos Litólicos, situados na sua porção nordeste e em pequena proporção (2,55\%). São considerados solos mais vulneráveis, pois apresentam um horizonte $A$ ou $O$ assentado diretamente sobre horizonte C ou sobre materiais com $90 \%$ ou mais da sua massa construída por fragmentos de rochas com diâmetro maior que $2 \mathrm{~mm}$, com contato lítico (rocha, camada R) dentro de $50 \mathrm{~cm}$ da superfície do solo.

\section{Geomorfologia}

No Rio Grande do Sul, segundo o IBGE (2003b), são encontrados três Domínios Morfoestruturais: Domínio Morfoestrutural dos Depósitos Sedimentares Quaternários, Domínio Morfoestrutural das Bacias e Coberturas Sedimentares e Domínio Morfoestrutural dos Embasamentos em Estilos Complexos. A região norte do Estado está compreendida no subdomínio morfoestrutural da Bacia e Coberturas Sedimentares do Paraná, correspondendo a planaltos monoclinais, com inclinações para oeste em consequência do mergulho das rochas da Província Paraná (IFC, 2002). 
O município em estudo situa-se no domínio morfoestrutural da Bacia Sedimentar do Paraná, na unidade morfoescultural do Planalto das Araucárias. Nesta unidade de planaltos, as características morfológicas são definidas em função das diferenciações litológicas e da heterogeneidade. Essas diferenciações se referem principalmente à Formação Serra Geral, que compreende o substrato litológico fundamental, constituído por uma sequência espessa de rochas vulcânicas predominantemente básicas, mas também ácidas nas porções superiores dos derrames, bem como à cobertura de arenitos cenozóicos em sua porção sudeste, correspondente a Formação Tupanciretã (IFC, 2002).

Destaca-se também a presença das rochas efusivas ácidas e das rochas efusivas básicas em áreas distintas. As primeiras ocorrem principalmente em áreas mais planas e conservadas, com pequena amplitude altimétrica que acompanha os eixos da drenagem, sendo conhecidas regionalmente com o nome de Campos Gerais. Nas áreas onde ocorrem as rochas efusivas básicas, o relevo geralmente se apresenta dissecado, com vales profundos e encostas em patamares, caracterizando assim o que se denominou de Planalto Dissecado Rio Iguaçu - Rio Uruguai.

O mapa geomorfológico do município de Barão de Cotegipe, com detalhes na escala 1:50000, pode ser observado na Figura 3. Ele foi elaborado com base na morfografia (formas dos topos) e nos índices morfométricos referentes à variação altimétrica, e na intensidade de dissecação do relevo pela drenagem (dimensão interfluvial), segundo a metodologia proposta por Ross $(1992,1994)$. As unidades morfológicas foram definidas com base nos padrões das formas dos topos, e nas formas de agradação (Apf - planície fluvial) ou denudação ( $\mathrm{Da}$ - Formas com topos aguçados, Dc - Formas com topos convexos, Dp formas de superfícies planas e Dt - formas com topos tabulares), seguidas de um número referente aos índices morfométricos. 


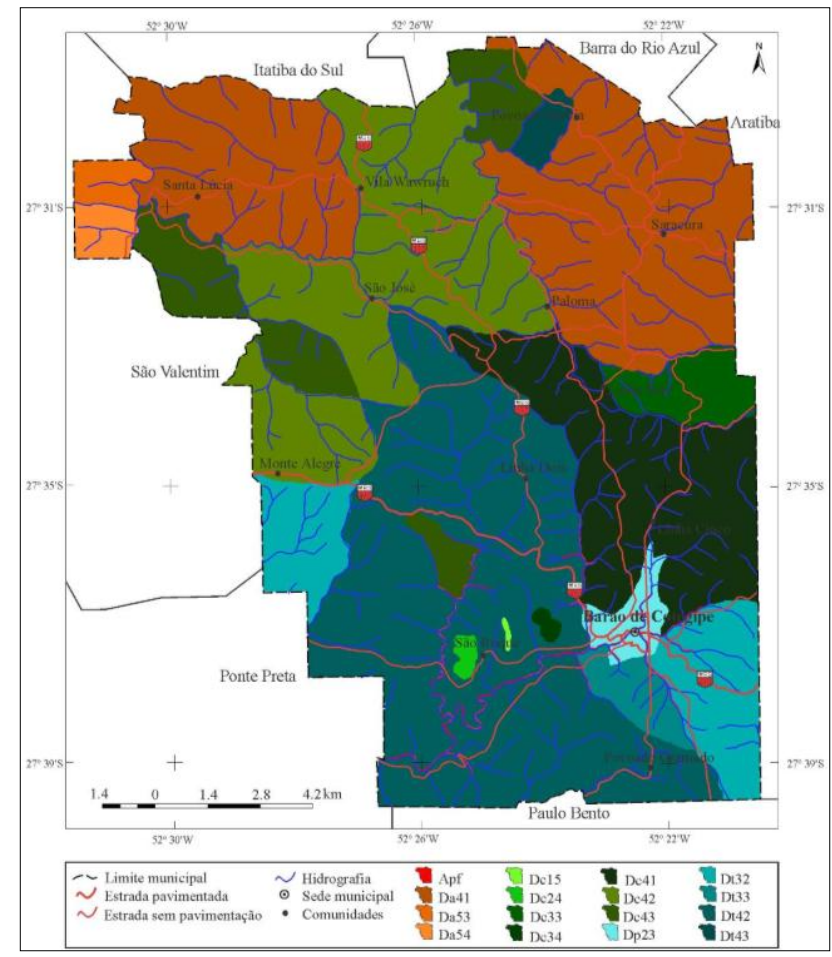

Figura 3: Mapa de Geomorfologia do município de Barão de Cotegipe/RS. Elaboração - Rovani (2013). Fonte - IBGE (2003b)

Ao observar a figura 3, verifica-se que as formas com topos tabulares estão situadas principalmente na porção sul e centro do município, nas áreas com grau de entalhamento entre 50 a 110 metros e com predomínio da baixa dimensão interfluvial na classe de 1750 a 3750 metros. Estas formas apresentaram valores de vulnerabilidade de estável à moderadamente estável, pois representam relevos suavemente ondulados e interflúvios tabulares.

As formas com topos convexos encontram-se principalmente no leste, noroeste e norte do município e em algumas áreas isoladas, predominaram nas áreas com grau de entalhamento médio a forte (50 a 110 m e 110 a 230 m respectivamente) e com dimensão interfluvial variada desde as classes muito alta $(<250 \mathrm{~m})$ até muito baixa (>3750 m). Pelo fato de serem áreas com relevos ondulados, dissecados em colinas, receberam valores de vulnerabilidade próximos a 2,0, caracterizando-se como medianamente estável/vulnerável.

A terceira forma com maior ocorrência refere-se às formas com topos aguçados, localizados principalmente na porção norte, caracterizando relevos fortemente ondulados a escarpados, dissecados em ravinas e cristas, e, assim, apresentando valores de vulnerabilidade próximos a 3,0. Apresentaram grau de entalhamento forte (110 a 230 metros) a muito forte (> 230 
metros) e dimensão interfluvial variada de muito baixa (>3750 m), média (750 a 1750 m) e alta $(250$ a $750 \mathrm{~m})$.

As formas de superfícies planas, localizadas na área urbana do município, receberam valores de vulnerabilidade da classe de moderadamente estável, por serem áreas relativamente planas, apresentarem grau de entalhamento fraco (20 a 50 m) e dimensão interfluvial média (750 a 1750 m). Por último, as formas de planície fluvial, situadas na porção sul do município, receberam valores de vulnerabilidade 3,0, sendo assim consideradas áreas vulneráveis, pois apresentam grande potencial de morfogênese.

\section{Geologia}

O mapa de geologia foi elaborado com base em IBGE (2003a), na escala 1:250000 e pode ser observado na Figura 4.

Com base na figura 4, verifica-se a presença de apenas uma classe do tema geologia, em função da escala original dos dados de 1:250000, denominada de Formação Serra Geral. Esta formação é constituída de rochas efusivas básicas, continentais, toleíticas, comumente basaltos e fenobasaltos. De acordo com IBGE (2003a), normalmente campeando as efusivas básicas, ocorre uma sequência de rochas de composição ácida constituída por riolitos felsíticos, riodacitos felsíticos, dacitos felsíticos e seus correspondentes termos vítreos.

Esta formação tem idade aproximada de 110 a 160 milhões de anos, com origem na Era Mesozóica, no Período Juro-Cretáceo, e pertence ao Grupo São Bento (Formações Rosário do Sul, Botucatu e Serra Geral). Caracteriza-se pela maior estabilidade com relação à perda natural de solo, pois as rochas que a constituem apresentam maior grau de coesão quando comparadas aos arenitos, aos xistos, aos siltítos, de menor grau de coesão, e prevalecem os processos modificadores das formas do relevo. 


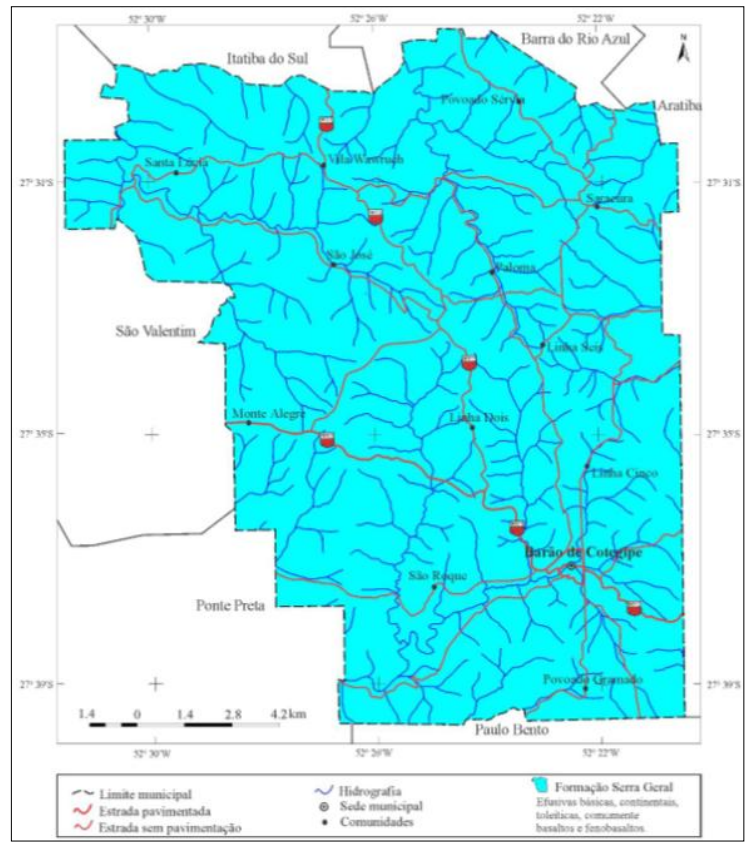

Figura 4: Mapa de Geologia do município de Barão de Cotegipe/RS. Elaboração - Rovani (2013). Fonte: IBGE (2003a).

\section{Uso e Cobertura da Terra e Vegetação}

O mapa de uso e cobertura da terra e vegetação (Figura 5) visou identificar os usos da terra e os tipos de vegetação presentes no município, com base na interpretação da imagem de satélite Landsat 5 e com o auxílio de trabalhos de campo.

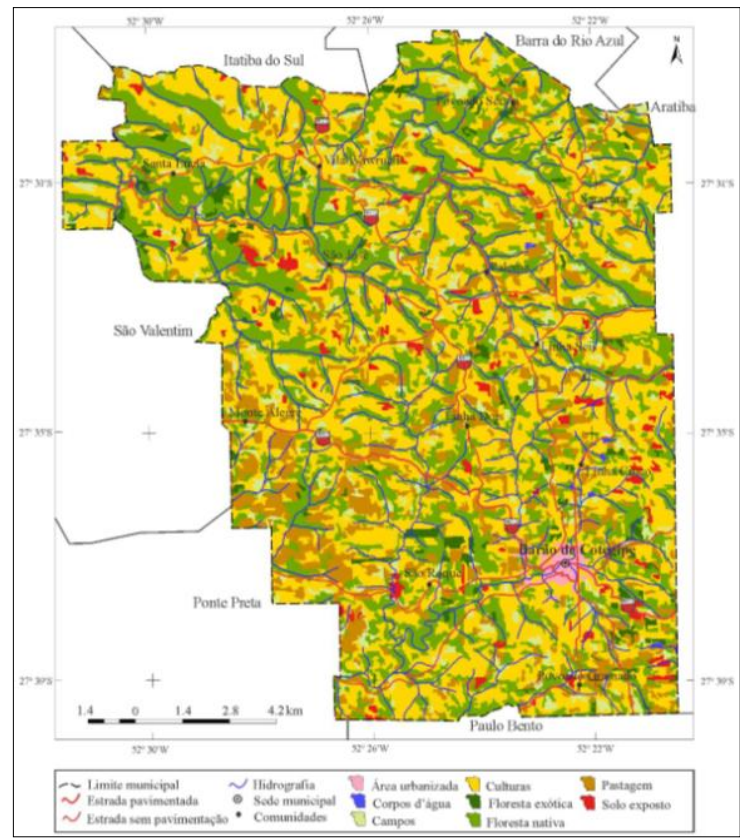

Figura 5: Mapa de Uso e Cobertura da Terra e Vegetação do município de Barão de Cotegipe/RS. Elaboração: Rovani (2013). Fonte: Imagem Landsat 5. 
Foram definidas oito classes de uso de maior relevância, e sua área de ocupação em hectares e em percentagem pode ser visualizada na Tabela 3.

\begin{tabular}{|l|c|c|}
\hline \multicolumn{1}{|c|}{ VEGETAÇÃo/USO DA TERRA } & ÁREA OCUPADA (ha) & ÁREA OCUPADA (\%) \\
\hline Área urbanizada & 170,38 & 0,65 \\
\hline Corpos d'água & 19,84 & 0,07 \\
\hline Campos & $1.237,92$ & 4,76 \\
\hline Culturas & $12.517,58$ & 48,14 \\
\hline Floresta nativa & $8.375,42$ & 32,21 \\
\hline Pastagem & $2.734,64$ & 10,51 \\
\hline Solo exposto & 451,51 & 1,73 \\
\hline Reflorestamento & 502,66 & 1,93 \\
\hline
\end{tabular}

Tabela 3: Classes de vegetação, uso e cobertura da terra e sua área ocupada em hectares e em percentagem.

Com base na figura 5 e na tabela 3, pode-se observar que o uso da terra de maior predominância no Município foi o das culturas, representando $48,14 \%$ da área total. Esta classe compreende as culturas temporárias, milho, soja, feijão e trigo, e as áreas com culturas permanentes, como a erva-mate, os pomares de cítricas e os parreirais. Estas culturas, distribuídas de forma heterogênea em toda área de estudo, representam grau de vulnerabilidade relativamente alto, pois propiciam a perda de solo por meio das técnicas agrícolas de modo intensivo.

As áreas com floresta nativa, compreendendo a Floresta Ombrófila Mista (Floresta das Araucárias) e a Floresta Estacional Decidual (Floresta Subtropical do Alto Uruguai), correspondem a 32,21\% da área total. Elas estão situadas principalmente nas áreas de maior declividade, nas encostas, e, de maneira mais expressiva, na parte norte do Município, nas áreas de relevo mais acidentado, margeando o leito dos rios. Estas áreas, ainda que, em partes, já antropizadas, representam, na grande maioria, as Áreas de Preservação Permanente (APP) ainda existentes e, por isso, caracterizam-se como áreas mais estáveis.

A terceira classe que aparece em maior proporção é a das pastagens (10,51\%), plantadas principalmente neste período de análise. Estas áreas distribuídas de modo irregular são utilizadas principalmente para pastagens, para o gado leiteiro no inverno e, no verão, são utilizadas para o cultivo de culturas como milho, soja ou feijão. Devido a este tipo de uso, elas correspondem ao grau de moderadamente vulnerável à perda de solo.

Os campos compreendem as áreas cobertas por gramíneas e pequenos arbustos durante o ano inteiro e são destinados à criação do gado de corte e, em parte, do gado leiteiro. Localizam-se em pequenas porções do município, representando $4,76 \%$ da área total, e 
também se constituem em áreas moderadamente vulneráveis, pois o pisoteio do gado, durante vários ciclos produtivos, intensifica a possibilidade de desenvolvimento de ravinas, valos e, assim, da erosão.

As áreas com floresta exótica representam 1,93\% da área municipal e estão em expansão, devido a incentivos para este cultivo, já que se caracteriza como um investimento rentável em longo prazo. As principais espécies cultivadas são de eucalipto e pinus, sendo que o primeiro ganha destaque na produção de madeira em toras e em lenha utilizadas na construção civil e em indústrias. Elas estão localizadas em algumas propriedades, como fonte de renda extra ou investimento futuro, e foram consideradas áreas medianamente estáveis / vulneráveis, pois, apesar de constituir uma cobertura vegetal mais duradoura, apresentam uso intensivo do solo.

A classe de uso de solo exposto corresponde àquelas áreas sem cobertura vegetal, que provavelmente estão em pousio e que serão utilizadas posteriormente para algum cultivo. Elas representam pequenas porções isoladas, perfazendo $1,73 \%$ da área total. Áreas com pouca ou sem cobertura vegetal se tornam potenciais áreas de lixiviação e perda do solo, sendo assim consideradas vulneráveis. $O$ indicado é que estas áreas recebam algum tipo de cobertura vegetal, como azevém ou aveia, para manter o solo coberto até o início do plantio das culturas temporárias.

A área urbanizada mapeada compreende o perímetro urbano definido pelos setores censitários, ela está situada a sudeste do município, representando 0,65\% de sua área total. Apresentou uma considerável expansão no decorrer dos anos, devido, sobretudo, ao êxodo rural intensivo, uma vez que a população do meio rural, frente às inúmeras dificuldades encontradas na produção agrícola, exigências de mercado e mão de obra escassa, encontrou no meio urbano a possibilidade de emprego assalariado e a certeza de uma renda mensal. Assim, essas áreas urbanas, com a impermeabilização do solo e ocupação muitas vezes inadequada, constituem-se em áreas vulneráveis à perda de solo.

Os corpos d'água basicamente constituídos por reservatórios artificiais, como açudes, são utilizados para consumo diário de água para a criação de gado, suínos e aves, além de serem destinados à piscicultura, em desenvolvimento no município, visto que ela se constitui num incentivo aos agricultores, a fim de dinamizarem a produção na propriedade. Estas áreas são 
consideradas moderadamente estáveis por não apresentarem significativos potenciais à perda de solo em relação às demais classes de uso.

\section{Mapa de Vulnerabilidade Natural à Perda de Solo}

O mapa de vulnerabilidade natural à perda do solo, resultante da integração das informações referentes aos valores de estabilidade/vulnerabilidade dos solos, da geomorfologia, da geologia e da vegetação e uso da terra com base nas UTBs, pode ser observado na Figura 6.

As classes de estabilidade e vulnerabilidade foram definidas de acordo com a tabela 2. As unidades que apresentaram valores entre 1,0 a 1,3 foram definidas como estáveis, as que apresentaram valores de 1,4 a 1,7 foram classificadas de moderadamente estável. Os valores no intervalo de 1,8 a 2,2 definiram a classe de medianamente estável/vulnerável, os valores entre 2,3 a 2,6 determinaram a classe de moderadamente vulnerável e, por fim, as unidades com valores entre 2,7 a 3,0 foram classificadas como vulneráveis.

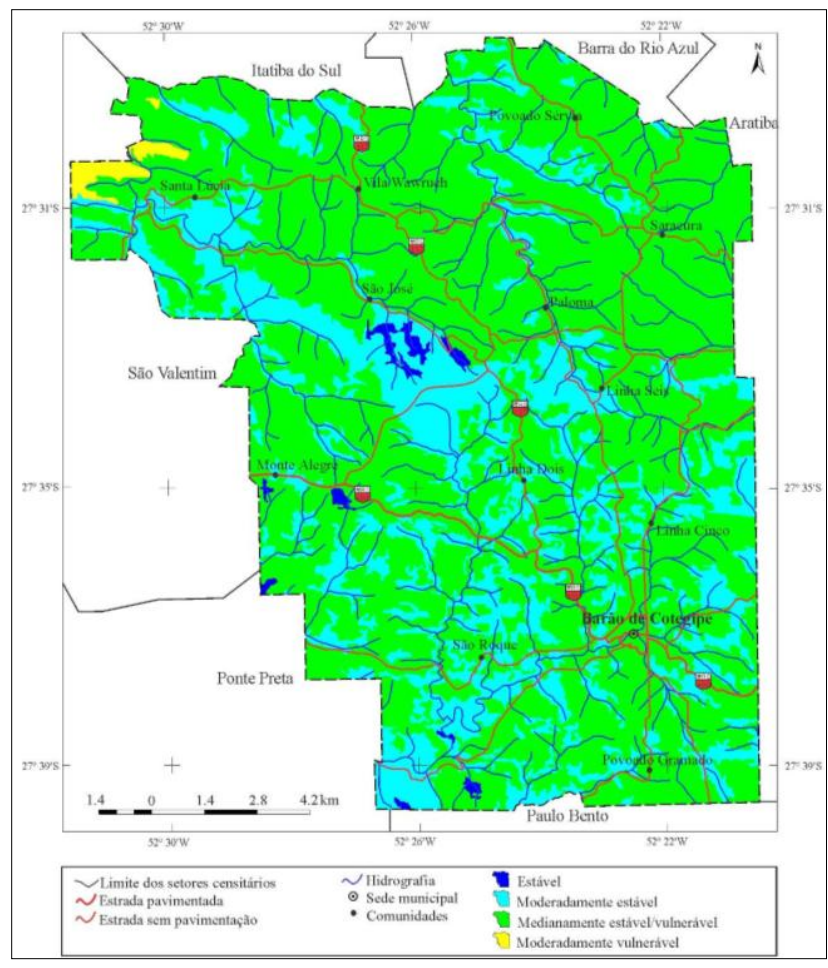

Figura 6: Mapa de Vulnerabilidade Natural à Perda de Solos do município de Barão de Cotegipe/RS.

Ao observar a Figura 6, pode-se verificar a presença de 4 classes de estabilidade/vulnerabilidade, variando desde a classe estável até a classe moderadamente vulnerável, com predomínio da classe medianamente estável/vulnerável. 
As UTBs mais estáveis (classe estável e moderadamente estável) à perda de solo representam as áreas relativamente homogêneas com relação às características de solo, geologia, geomorfologia, vegetação e uso da terra, totalizando $26,82 \%$ da área municipal. Estão situadas principalmente nas áreas com a presença de cobertura vegetal, especialmente das florestas nativas, em encostas e topos de morros convexos e tabulares. Além disso, caracterizam as unidades que apresentam maior estabilidade à perda de solo, em relação às demais, e desta forma devem ser preservadas.

As UTBs identificadas como mediamente estável/vulnerável, em maior proporção (72,53\%), estão na transição entre as unidades mais estáveis e as mais vulneráveis, sendo encontradas na maior parte do território. Na porção norte do município, prevaleceu a classe mediamente estável por compreender unidades com solos do tipo cambissolo háplicos, topos de morros aguçados, convexos e presença da floresta nativa e culturas. As unidades classificadas como medianamente vulneráveis predominaram na porção leste, oeste e sul, com características muito próximas às anteriores, porém se diferenciando com os solos do tipo latossolo bruno, topos de morros tabulares e convexos e menor ocorrência de vegetação. Estas são unidades que representam um equilíbrio entre a pedogênese e morfogênese.

Por seguinte, apresentam-se as unidades classificadas como moderadamente vulneráveis $(0,71 \%)$ e que requerem maiores cuidados, pois nelas predominam os processos de morfogênese, modificadores do relevo. Em especial, identificaram-se unidades na parte noroeste do município, com a presença de solos do tipo neossolo litólico, topos de morros aguçados e com a presença de vegetação e culturas.

\section{CONSIDERAÇÕES FINAIS}

A análise integrada dos dados relativos aos solos, à geomorfologia, à geologia, à vegetação e uso da terra resultou no mapa de vulnerabilidade natural à perda do solo. A partir deste mapa síntese, foi possível identificar e analisar a estabilidade e a vulnerabilidade das unidades (UTBs) baseadas no conceito de ecodinâmica, fundamentadas na relação morfogênese e pedogêse, e da potencialidade para estudos integrados, das imagens de satélite Landsat. No Município, foram identificadas unidades consideradas estáveis, com 
predomínio dos processos formadores do solo, e unidades moderadamente vulneráveis, prevalecendo os processos erosivos.

No entanto, predominaram as unidades identificadas como mediamente estável/vulnerável, ocupando $72,53 \%$ da área total municipal, representando um equilíbrio entre a pedogênese e a morfogênese. As UTBs mais estáveis à perda do solo totalizam $26,82 \%$ da área e localizam-se principalmente nas áreas com a presença de cobertura vegetal, especialmente das florestas nativas em encostas e topos de morros convexos e tabulares e que devem ser preservadas. As UTBs moderadamente vulneráveis (0,71\%), identificadas na porção noroeste no município, requerem maior atenção, pois predominam os processos de morfogênese, modificadores do relevo, sobretudo pela presença de solos mais instáveis e presença das culturas agrícolas.

Desse modo, esta pesquisa apresentou as unidades de paisagem encontradas no município de Barão de Cotegipe, por meio da integração dos aspectos ambientais, com o auxílio das técnicas de geoprocessamento e sensoriamento remoto integradas ao SIG, de maneira eficaz e adequada a esta metodologia. Além disso, norteados pelos princípios da Cartografia Ambiental, as unidades foram representadas cartograficamente, permitindo a compreensão e a visualização das interações do meio ambiente e da dinâmica do social com o meio natural.

\section{AGRADECIMENTOS}

Agradecemos a Coordenação de Aperfeiçoamento de Pessoal de Ensino Superior (CAPES) pela concessão da bolsa de mestrado do primeiro autor.

\section{BIBLIOGRAFIA}

IBGE. Geologia. Erechim/Lages SG.22-Y-D/Z-C. Rio de Janeiro: IBGE, 2003a. 1 mapa. Escala: $1 / 250000$. Disponível em: <ftp://geoftp.ibge.gov.br/mapas_tematicos/geologia/cartas_escala_250mil/sg22yd_zc_geol. pdf>. Acesso em: 09 jul. 2012.

IBGE. Geomorfologia. Erechim/Lages SG.22-Y-D/Z-C. Rio de Janeiro: IBGE, 2003b. 1 mapa. Escala: $1 / 250000$. Disponível

em: <ftp://geoftp.ibge.gov.br/mapas_tematicos/geomorfologia/cartas_escala_250mil/sg22yd_zc _geom.pdf>. Acesso em: 09 jul. 2012. 
IBGE. Solos. Erechim/Lages SG.22-Y-D/Z-C. Rio de Janeiro: IBGE, 2003c. 1 mapa. Escala: $1 / 250000$. Disponível

em: <ftp://geoftp.ibge.gov.br/mapas_tematicos/pedologia/cartas_escala_250mil/sg22yd_zc_pe d.pdf>. Acesso em: 09 jul. 2012.

BECKER, B. K.; EGLER, C. A. G. Detalhamento da Metodologia para Execução do Zoneamento Ecológico Econômico pelos Estados da Amazônia Legal. Brasília: SAE/MMA, 1996.

CAMPAGNANI, S.; SANTOS, U. P. dos. Programa de Zoneamento Ecológico-Econômico do estado do Rio de Janeiro. Projeto II: Zoneamento Ecológico-Econômico do Médio Vale do Paraíba. Rio de Janeiro, 1998.

CREPANI, E. et al. Curso de Sensoriamento Remoto Aplicado ao Zoneamento EcológicoEconômico. São José dos Campos: INPE, 1996.

CREPANI, E. et al. Zoneamento Ecológico-Econômico. In: FLORENZANO, T. G. (Org.). Geomorfologia: conceitos e tecnologias atuais. São Paulo: Oficina de Textos, 2008. p. 285318.

EMBRAPA. Sistema brasileiro de classificação de solos. Rio de Janeiro: Embrapa Solos, 2006.

IFC. Inventário Florestal Contínuo. Santa Maria: UFSM/SEMA-RS, 2002. Disponível em: <http://coralx.ufsm.br/ifcrs/frame.htm>. Acesso em: 10 jan. 2013.

LIMA, F. R.; MARTINELLI, M. As unidades ecodinâmicas na Cartografia Ambiental de Síntese. In: SIMPÓSIO DE PÓS-GRADUAÇÃO EM GEOGRAFIA DO ESTADO DE SÃO PAULO, 2008, Rio Claro. Anais eletrônicos... Rio Claro: UNESP, 2008. Disponível em: <http://www.rc.unesp.br/igce/simpgeo/440-448fredy.pdf>. Acesso em: 12 abr. 2011.

MEDEIROS, J. S. de. Bancos de dados geográficos e redes neurais artificiais: tecnologias de apoio à gestão do território. Tese (Doutorado em Geografia Física) - Universidade de São Paulo, São Paulo, 1999.

ROSS, J. L. S. O registro cartográfico dos fatos geomórficos e a questão da taxonomia do relevo. Revista do Departamento de Geografia, São Paulo, n. 6, p. 17-29, 1992.

ROSS, J. L. S. Análise empírica da fragilidade dos ambientes naturais e antropizados. Revista do Departamento de Geografia, São Paulo, n. 6, p. 63-74, 1994.

ROVANI, F. F. M. Cartografia Ambiental de Barão de Cotegipe, RS: subsídios para o planejamento municipal. 2013. 158 p. Dissertação (Mestrado em Geografia) - Universidade Federal de Santa Maria, Santa Maria, 2013.

SIMÕES, M. et al. Metodologia para elaboração do Zoneamento Ecológico-Econômico em áreas com grande influência antrópica. Rio de Janeiro, 1998. Disponível em: <http://www.laget.igeo.ufrj.br/egler/pdf/maggie.pdf>. Acesso em 02 fev. 2012.

STRECK, E. V. et al. Solos do Rio Grande do Sul. Porto Alegre: EMATER/RS-ASCAR, 2008.

TRICART, J. Ecodinâmica. Rio de Janeiro: IBGE, 1977.

\begin{tabular}{|r|r|}
\hline Artigo submetido em & $29 / 09 / 2014$ \\
\hline Artigo aceito em & $21 / 01 / 2015$ \\
\hline
\end{tabular}

